\title{
Cervical congenital infantile fibrosarcoma: a case report
}

\author{
Alisha Gupta', Shilpa Sharma ${ }^{1 *}$, Sandeep Mathur ${ }^{2}$ D. K. Yadav ${ }^{1}$ and D. K. Gupta ${ }^{1}$
}

\begin{abstract}
Background: Congenital infantile fibrosarcoma is a rare mesenchymal tumor seen in children as well as adults. The congenital variety is rare and out of the reported cases only one case sited in the neck has been reported so far. Another such case is presented here who was successfully managed.

Case presentation: A 3-month-old Hindu baby boy presented with a congenital neck swelling. The apparent clinical diagnosis was lympho-venous malformation. With a remote possibility of malignancy, an excisional biopsy was done. Histopathology revealed congenital infantile fibrosarcoma.

Conclusion: A successful excision of cervical congenital infantile fibrosarcoma has not been reported. This diagnosis should be kept as a possibility in all congenital cervical swellings. These are commonly misdiagnosed as lympho-venous malformations and histopathology is confirmatory.
\end{abstract}

Keywords: Infantile fibrosarcoma, Neck, Infant

\section{Background}

Congenital infantile fibrosarcoma (CIFS) is a rare mesenchymal tumor which, contrary to its name, is seen both in children as well as adults. The congenital variety is even rarer with only a few reported cases. Among the sites of origin of these congenital lesions, occurrence in the neck has been reported only once before [1]. The case reported earlier had died during surgery due to exsanguinating hemorrhage [1]. We report here a successful excision of the lesion. The case is discussed with a review of recent literature.

\section{Case presentation}

A 3-month-old Hindu baby boy presented with a congenital neck swelling on the right side of his neck. There was no history of birth trauma or breech delivery. Initially a small midline swelling, it progressively increased in size with age. It was soft and compressible with an overlying bluish hue at places. With a working diagnosis of a low flow lymphovascular malformation at another hospital, intralesional bleomycin was injected once after which the swelling became a little firm without any change in its size. One

\footnotetext{
*Correspondence: drshilpas@gmail.com

${ }^{1}$ Department of Pediatric Surgery, All India Institute of Medical Sciences, New Delhi, India

Full list of author information is available at the end of the article
}

month after the bleomycin injection, it was a $5.5 \times 7.5 \mathrm{~cm}$ firm, non-tender, well-defined swelling in the midline and extending into the right supraclavicular region (Fig. 1). There was no retrosternal extension and no movement with deglutition or cervical lymphadenopathy. Imaging suggested a diagnosis of lympho-venous malformation (Fig. 2). However, there was a remote suspicion of malignancy as there were interspersed solid areas. Serum alphafetoprotein levels were in the normal range for age. On exploration, a friable, solid mass with a pseudocapsule was encountered without any cystic component. It encased the sternal head of right sternocleidomastoid, part of which had to be sacrificed. A frozen section sent during excision was suggestive of malignancy. Complete gross resection of the lesion was done. There were no obviously enlarged neck nodes. Histopathology revealed a tumor comprising spindle-shaped fibroblast-like cells along with large areas of hemorrhage (Fig. 3). Tumor cells were arranged in fascicles and at places in a herringbone pattern. There was brisk mitotic activity and moderate degree of anisonucleosis. Cells were immunopositive for desmin but negative for myogenin, smooth muscle actin (SMA), pancytokeratin, epithelial membrane antigen (EMA), MIC-2, and CD-34. Sternocleidomastoid muscle was free of tumor. The diagnosis of CIFS was favored over spindle cell rhabdomyosarcoma in view of absence of myogenin positivity. A 


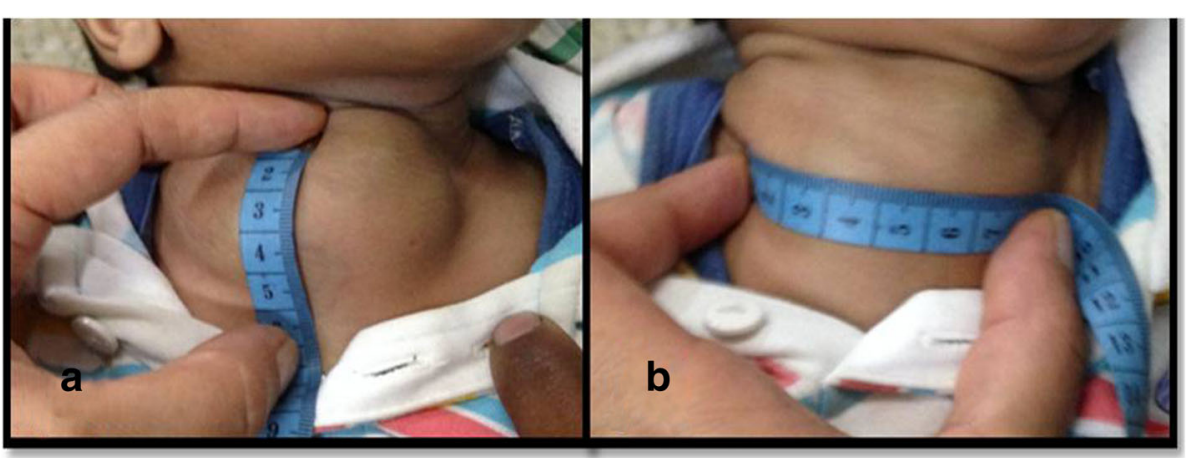

Fig. 1 a and $\mathbf{b}$ Clinical photograph showing a $5.5 \times 7.5 \mathrm{~cm}$ neck mass (right supraclavicular) with bluish hue at places - clinically suspected to be a slow flow vascular malformation

metastatic workup was negative. No chemoradiotherapy was initiated and the child was kept under close follow-up. A follow-up contrast-enhanced computed tomography scan (CECT) of his neck and chest showed no residue or recurrence at 3 and 6 months. He is thriving well and was disease free at 2-year follow-up.

\section{Discussion and conclusions}

CIFS is one of the common non-rhabdomyosarcoma soft tissue tumors in children with an incidence of around 5 per million cases in the pediatric age group [2]. Although only 100 cases were reported until 2009 in children, with $\sim 40 \%$ present at birth, the entity has been diagnosed in the antenatal period $[1,3,4]$.
Although the most common site of occurrence is in the distal extremities, rare locations such as lung, heart, tongue, chest wall, presacral region, and retroperitoneum have also been reported [5-9]. The congenital and adult types of infantile fibrosarcoma, although histologically similar, differ in their clinical presentation in that the adult type has a higher risk of recurrence, higher incidence of metastasis, and fairs poorly in the overall survival.

The differential diagnoses include a wide range of fibroblastic and myofibroblastic tumors. Pediatric fibroblastic and myofibroblastic tumors on the basis of their biologic behavior have been divided into various entities [10]. These have been outlined in Table 1.

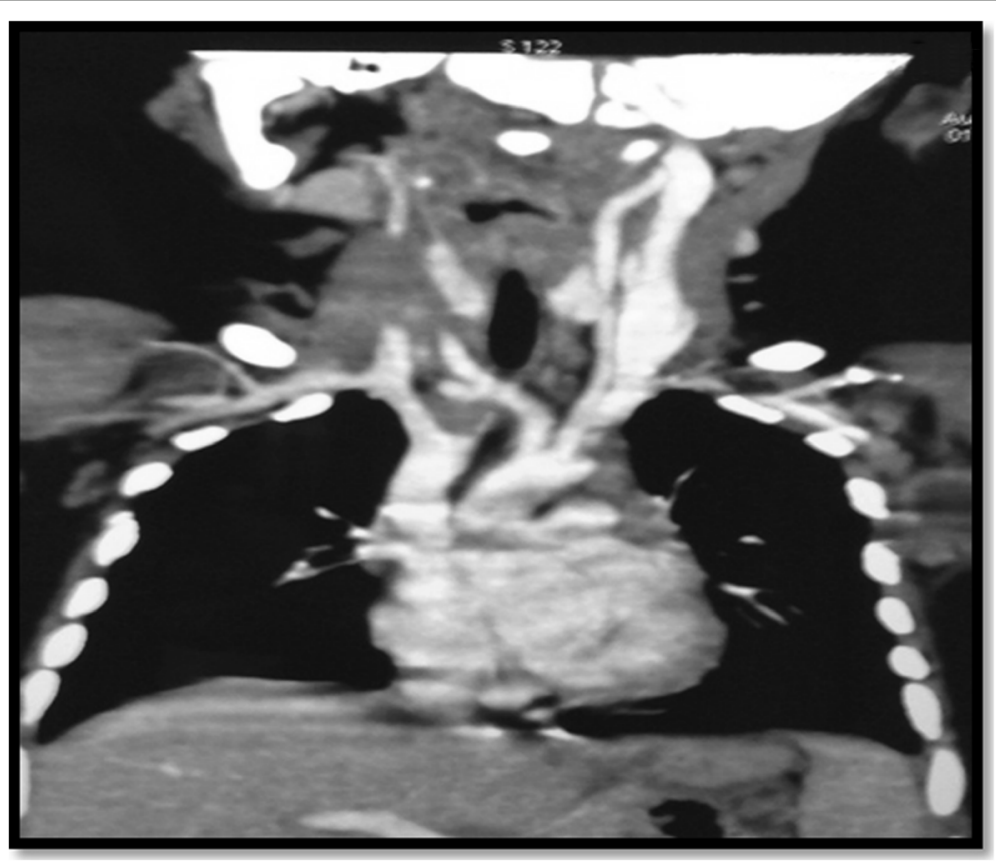

Fig. 2 Contrast-enhanced computed tomography of the neck and chest showing a highly vascular heterogenous soft tissue lesion, pushing the neck vessels posteriorly with no retrosternal extension 


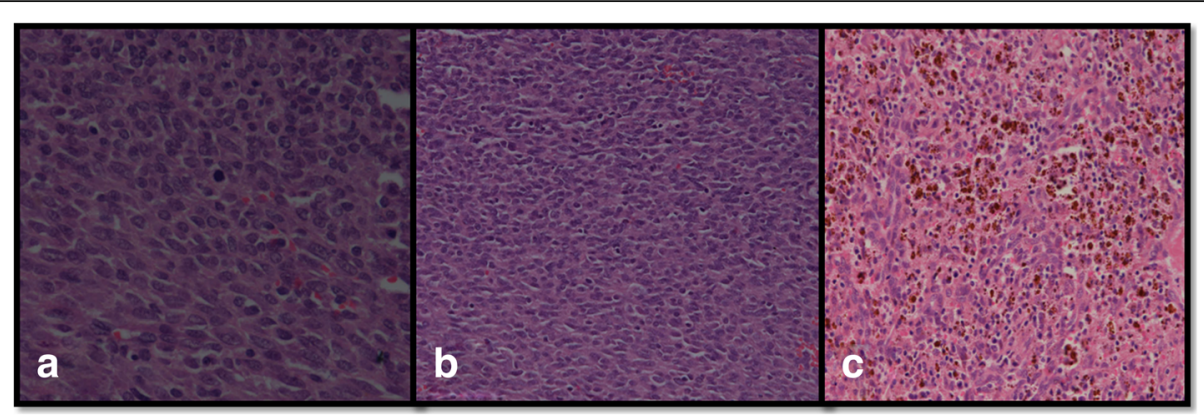

Fig. 3 Photomicrographs showing histopathological findings of a presence of mitotic figures, $\mathbf{b}$ spindle-shaped cells, and $\mathbf{c}$ hemosiderin-laden macrophages

Composite infantile myofibromatosis of the scalp with several distinct histopathological features including myofibroma, hemangiopericytoma, and fibrosarcoma have been described in newborns [11]. An infantile rhabdomyofibrosarcoma that lies intermediately between rhabdomyosarcoma and infantile fibrosarcoma in terms of clinical presentation, immunohistochemistry, behavior, morphology, and ultrastructural features has been reported in a 26-month-old girl [12].

CIFSs, being vascular lesions, have been notoriously misdiagnosed as hemangiomas and lympho-venous malformations at birth and earlier, as was seen in the present case $[1,13]$. Suspicious cutaneous lesions may be diagnosed with a biopsy. Occasional cases of hypercalcemia of malignancy in a newborn with infantile fibrosarcoma have been described $[1,14]$. The expression of parathyroid hormone/parathyroid hormone-related protein (PTH/ PTH-rP) receptor messenger ribonucleic acid has been detected in the tumor by reverse transcription-polymerase chain reaction (RT-PCR), suggesting the effect of PTH-rP in the tumor in an autocrine/paracrine manner [1]. It has been suggested that in addition to the systemic effect of PTH-rP manifested as hypercalcemia, the PTH-rP secreted from the neoplasm could be a local factor involved in the growth of the tumor and enhanced vascularity leading it to mimic a vascular lesion-like hemangioma [1].

Wide local excision, without any mutilating surgery, is the mainstay of management [15]. In cases of huge tumor size, where functional or anatomical derangement might jeopardize the quality of life in these children, neoadjuvant chemotherapy with vincristine and actinomycin-D (VA) might prove beneficial $[3,16]$. In cases, where a tumor-free margin is achieved, close follow-up without any adjuvant chemotherapy is sufficient. Although the role of adjuvant chemotherapy has not been established, chemotherapy has been used postoperatively in cases with positive surgical margins or with residual tumor $[17,18]$. In the present case, complete gross excision with tumor-free margin was achieved and hence the child was kept on close follow-up only.

The European Pediatric Soft Tissue Sarcoma Study Group (Intergroup Rhabdomyosarcoma Study; IRS) has developed conservative treatment recommendations according to initial resectability of the tumor [19]. Initial surgery is suggested only if possible without mutilation. Patients with initial complete (IRS group I/R0) or microscopic incomplete (group II/R1) resection have no further therapy. Patients with initial inoperable tumor (group III/ R2) receive first-line VA chemotherapy. Delayed conservative surgery is planned after tumor reduction. Aggressive local therapy (mutilating surgery or external radiotherapy) is discouraged. The VA regimen is recommended as the first-line therapy in order to reduce long-term effects [19].

Although CIFSs are biologically more benign than their counterparts occurring in older patients, they are histologically similar. CIFSs belong to one end of a spectrum of

Table 1 Types of pediatric fibroblastic and myofibroblastic tumors

\begin{tabular}{|c|c|c|}
\hline Group & Types & Characteristics \\
\hline Benign & $\begin{array}{l}\text { Myositis ossificans } \\
\text { Myofibroma } \\
\text { Fibromatosis colli }\end{array}$ & $\begin{array}{l}\text { Great toe malformations in fibrodysplasia ossificans fibroma, } \\
\text { neonatal torticollis in fibromatosis colli }\end{array}$ \\
\hline Intermediate-locally aggressive & $\begin{array}{l}\text { Lipofibromatosis } \\
\text { Desmoid fibroma }\end{array}$ & $\begin{array}{l}\text { Adipose tissue in lipofibromatosis, plaque-like growth pattern } \\
\text { of Gardner fibroma }\end{array}$ \\
\hline Intermediate-rarely metastasizing & $\begin{array}{l}\text { Inflammatory myofibroblastic tumors } \\
\text { Infantile fibrosarcoma } \\
\text { Low-grade myofibroblastic sarcoma }\end{array}$ & $\begin{array}{l}\text { Low or intermediate signal intensity on T2-weighted magnetic } \\
\text { resonance images and extension along fascial planes is seen in } \\
\text { fibroblastic or myofibroblastic lesions, multiple subcutaneous or } \\
\text { intramuscular lesions may be seen in infantile myofibromatosis }\end{array}$ \\
\hline Malignant & $\begin{array}{l}\text { Fibromyxoid sarcoma } \\
\text { Adult fibrosarcoma }\end{array}$ & \\
\hline
\end{tabular}


fibrous proliferations occurring in children. Gains of chromosomes $8,11,17$, and 20 (in various combinations) were observed in 11 of 12 fibrosarcomas occurring in infants under 2 years of age [20]. Extra copies of chromosomes 17 and 20 were observed in a fibrosarcoma occurring in a 5 -year-old child but no abnormalities were detected by fluorescence in situ hybridization (FISH) in four additional fibrosarcomas occurring in patients aged 6-17 years. One of three cellular fibromatoses was characterized by extra copies of chromosome 8,11, 17, and 20. Similar findings were not observed in any of the noncellular fibromatoses or in myofibromatoses [20]. The ETS variant gene 6-neurotrophin 3 receptor gene (ETV6-NTRK3) gene fusion product identified by RT-PCR has been recognized as diagnostic of infantile fibrosarcoma. ETV6-NTRK3 transcript was present in $87.2 \%$ of patients where the investigation was performed by the European Pediatric Soft Tissue Sarcoma Study Group [19]. Pavlick et al. found that 9 out of 2031 advanced cancers from patients less than 21-years old (0.44\%) harbored NTRK fusions [21]. Notably, four of these cases were in children less than 2-years old for which infantile fibrosarcoma was considered a diagnosis, and two harbored the canonical ETV6-NTRK3 [21]. NTRK fusions occur in a subset of young patients with mesenchymal or sarcoma-like tumors at a low frequency, and are potential good targets for drugs. A case of refractory infantile fibrosarcoma (IFS) with constitutive activation of the tropomyosin-related kinase (TRK) signaling pathway from an ETV6-NTRK3 gene fusion experienced a rapid, radiographic response, thus depicting the potential for LOXO-101 (also known as larotrectinib) to provide benefit for IFS harboring NTRK gene fusions [22].

Histopathologic characteristics include a solid, dense proliferation of spindle cells in interlacing bundles; positive for vimentin, and occasionally for desmin, SMA, and cytokeratin [23]. Similar findings were observed in the present case. We could not test for the ETV6-NTRK3 gene fusion due to technical resource constraints.

The incidence of metastatic spread of disease is $5-8 \%$ [24]. The organs commonly affected in metastasis are the lungs and lymph nodes. Metastatic disease may be demonstrated on fluorodeoxyglucose positron emission tomography-computed tomography [25]. The risk of recurrence is considerably high, being $17-43 \%$ [26]. The prognosis is fair with a reported 5-year overall survival rate as high as $84-93 \%$ [27].

To conclude, CIFSs should be kept in the differential diagnoses of soft tissue tumors in infants, even in congenital cases. The clinical picture is similar to lymphovascular malformations which might lead to misdiagnosis of these tumors. The mainstay of treatment is complete excision. However, chemotherapy does have a good response and can be a preferred option if surgery is not possible without major anatomical compromise. Overall survival in these tumors is excellent.

\section{Abbreviations \\ CECT: Contrast-enhanced computed tomography; CIFS: Congenital infantile fibrosarcoma; EMA: Epithelial membrane antigen; ETV6-NTRK3: ETS variant gene 6-neurotrophin 3 receptor gene; FISH: Fluorescence in situ \\ hybridization; IFS: Infantile fibrosarcoma; IRS: Intergroup Rhabdomyosarcoma Study; PTH/PTH-rP: Parathyroid hormone/parathyroid hormone-related pro- tein; RT-PCR: Reverse transcription-polymerase chain reaction; High school: Smooth muscle actin; TRK: Tropomyosin-related kinase; VA: Vincristine and actinomycin-D}

\section{Acknowledgements}

Not applicable.

\section{Funding}

Department of Biotechnology. BT/PR9572/MED/97/210/2013 dated 24/06/ 2014.

Availability of data and materials

All data generated and analyzed in the study are included in the published article.

\section{Authors' contributions}

AG drafted the manuscript and reviewed the literature. SS managed the patient, reviewed the literature, and edited and revised the manuscript. SM studied the histopathology slides and confirmed the diagnosis. DKY and DKG helped in managing the patient. All authors read and approved the final manuscript.

Ethics approval and consent to participate

Not applicable as single case report. No human or animal tissue involved.

\section{Consent for publication}

Written informed consent for use of patient data, images, and publication was taken from the father of the child. A copy of the written consent is available for review by the Editor-in-Chief of this journal.

\section{Competing interests}

The authors declare that they have no competing interests.

\section{Publisher's Note}

Springer Nature remains neutral with regard to jurisdictional claims in published maps and institutional affiliations.

\section{Author details}

${ }^{1}$ Department of Pediatric Surgery, All India Institute of Medical Sciences, New Delhi, India. ${ }^{2}$ Department of Pathology, All India Institute of Medical Sciences, New Delhi, India.

Received: 18 September 2017 Accepted: 2 January 2019

Published online: 24 February 2019

\section{References}

1. Michigami T, Yamato H, Mushiake S, Nakayama M, Yoneda A, Satomura K, et al. Hypercalcemia Associated With Infantile Fibrosarcoma Producing Parathyroid Hormone-Related Protein. J Clin Endocrinol Metab. 1996;81: 1090-5.

2. Ries LAG, Smith MA, Gurney JG, Linet M, Tamra T, Young JL, et al. Cancer incidence and survival among children and adolescents: United States SEER program 1975-1995. Bethesda: Cancer Statistics Branch, National Cancer Institute; 1999.

3. Minard-Colin V, Orbach D, Martelli H, Bodemer C, Oberlin O. Soft tissue tumors in neonates. Arch Pediatr. 2009;16:1039-48.

4. Dumont C, Monforte M, Flandrin A, Couture A, Tichit R, Boulot P. Prenatal management of congenital infantile fibrosarcoma: unexpected outcome. Ultrasound Obstet Gynecol. 2011;37:733-5.

5. Kite AC, Rotstein LM, Rhodes IL. A Case Report of an Invasive Infantile Fibrosarcoma of the Forearm. Eplasty. 2016;16:36. 
6. Wahid Fl, Zada B, Rafique G. Infantile Fibrosarcoma of Tongue: A Rare Tumor. APSP J Case Rep. 2016;7:23.

7. Pandey A, Kureel SN, Bappavad RP. Chest Wall Infantile Fibrosarcomas - A Rare Presentation. Indian J Surg Oncol. 2016;7:127-9.

8. Hashemi A, Tefagh S, Seifadini A, Moghimi M. Infantile Fibrosarcoma in a Child: a Case Report. Iran J Ped Hematol Oncol. 2013;3:135-7.

9. Al-Salem AH. Congenital-infantile fibrosarcoma masquerading as sacrococcygeal teratoma. J Pediatr Surg. 2011;46:2177-80.

10. Sargar KM, Sheybani EF, Shenoy A, Aranake-Chrisinger J, Khanna G. Pediatric Fibroblastic and Myofibroblastic Tumors: A Pictorial Review. Radiographics. 2016:36:1195-214.

11. Ivanov A, Valyi-Nagy T, Nikas D. Extracalvarial Composite Infantile Myofibromatosis: Case Report and Literature Review. European J Pediatr Surg Rep. 2016:4:22-5.

12. Pan T, Chen K, Jiang RS, Zhao ZY. Misdiagnosed infantile rhabdomyofibrosarcoma: A case report. Oncol Lett. 2016;12:2766-8.

13. Enos T, Hosler GA, Uddin N, Mir A. Congenital infantile fibrosarcoma mimicking a cutaneous vascular lesion: a case report and review of the literature. J Cutan Pathol. 2017:44:193-200.

14. Agrawal S, Topor LS. Hypercalcemia of Malignancy in a Newborn with Infantile Fibrosarcoma. R I Med J (2013). 2016;99:32-3.

15. Chung EB, Enzinger FM. Infantile fibrosarcoma. Cancer. 1976;38:729-39.

16. Orbach D, Rey A, Cecchetto G, Oberlin O, Casanova M, Thebaud E, et al. Infantile fibrosarcoma: management based on the European experience. $J$ Clin Oncol. 2010;28:318-23.

17. Loh ML, Ahn P, Perez-Atayde AR, Gebhardt MC, Shamberger RC, Grier HE. Treatment of infantile fibrosarcoma with chemotherapy and surgery: results from the Dana-Farber Cancer Institute and Children's Hospital, Boston. J Pediatr Hematol Oncol. 2002;24:722-6.

18. Ninane J, Rombouts JJ, Cornu G. Chemotherapy for infantile fibrosarcoma. Med Pediatr Oncol. 1991;19:209.

19. Orbach D, Brennan B, De Paoli A, Gallego S, Mudry P, Francotte N, et al. Conservative strategy in infantile fibrosarcoma is possible: The European Paediatric Soft Tissue Sarcoma Study Group experience. Eur J Cancer. 2016; 57:1-9.

20. Schofield DE, Fletcher JA, Grier HE, Yunis EJ. Fibrosarcoma in infants and children. Application of new techniques. Am J Surg Pathol. 1994;18:14-24.

21. Pavlick D, Schrock AB, Malicki D, Stephens PJ, Kuo DJ, Ahn H, et al. Identification of NTRK fusions in pediatric mesenchymal tumors. Pediatr Blood Cancer. 2017;64 https://doi.org/10.1002/pbc.26433.

22. Nagasubramanian R, Wei J, Gordon P, Rastatter JC, Cox MC, Pappo A. Infantile Fibrosarcoma With NTRK3-ETV6 Fusion Successfully Treated With the Tropomyosin-Related Kinase Inhibitor LOXO-101. Pediatr Blood Cancer 2016:63:1468-70

23. Kihara S, Nehlsen-Cannarella N, Kirsch WM, Chase D, Garvin AJ. A comparative study of apoptosis and cell proliferation in infantile and adult fibrosarcomas. Am J Clin Pathol. 1996;106:493-7.

24. Tiraje C, Alp Ö, Hilmi A, Birol H, Sergülen D, Lebriz Y, et al. Two different clinical presentations of infantile fibrosarcoma. Turk J Cancer. 2000;30:81-5.

25. Bedmutha A, Singh N, Shivdasani D, Gupta N. Unusual case of infantile fibrosarcoma evaluated on F-18 fluorodeoxyglucose positron emission tomography-computed tomography. Indian J Nucl Med. 2016;31:201-3.

26. Shetty AK, Yu LC, Gardner RV, Warrier RP. Role of chemotherapy in the treatment of infantile fibrosarcoma. Med Pediatr Oncol. 1999;33:425-7.

27. Demir HA, Akyüz C, Varan A, Ergen FB, Büyükpamukçu M. Right foot congenital infantile fibrosarcoma treated only with chemotherapy. Pediatr Blood Cancer. 2010:54:618-20.

Ready to submit your research? Choose BMC and benefit from:

- fast, convenient online submission

- thorough peer review by experienced researchers in your field

- rapid publication on acceptance

- support for research data, including large and complex data types

- gold Open Access which fosters wider collaboration and increased citations

- maximum visibility for your research: over $100 \mathrm{M}$ website views per year

At $\mathrm{BMC}$, research is always in progress.

Learn more biomedcentral.com/submissions 